\title{
PENGARUH DAYA TARIK WISATA TERHADAP MINAT KUNJUNGAN WISATAWAN DI SERULINGMAS INTERACTIC ZOO PADA SAAT DIKELOLA PIHAK BUMD
}

\author{
Siti Maesaroh $^{1}$, Isna Maulana Cahyaningrum ${ }^{2}$ \\ STIE Tamansiswa Banjarnegara J1. Mayjend Panjaitan No.29 Banjarnegara \\ Email : sitimaesaroh@stietsbanjarnegara.ac.id ${ }^{1}$; maulana.isnac@gmail.com²
}

\begin{abstract}
This research aims to determine the influence of tourist attraction partially and simultaneous to the interest of visitors the facilities, services, tourist destinations and event in Serulingmas Interactive Zoo.

The method in this sampling is used the Slovin formula, data analysis methods used is multiple linear regression analyses, using the help of SPSS programmes. The test results of the hypothesis, indicating that the facility variable (X1) has a significant positive effect on the interest of visitors. The service variables (X2) have significant positive impact on the interest of visitors. The tourist destination variables $(X 3)$ is not significant to the interest of visitors. Event variables (X4) is not significant to the interest of visitors.

Based on the results of the research can be partially inferred that there is a positive and significant relationship between facilities and the interest of visitors, there is a positive and significant relationship between the service and the interest of visitors, there is a positive and insignificant relationship between tourist destinations and the interest of visitors, there is a positive and insignificant relationship between events and the interest of visitors. Simultaneously all variables are influential and significant to the interest of visitors. This determination test $\left(R^{2}\right)$ shows that a variable of visitors interest can be influenced by variable facilities, services, tourist destinations and events while the rest are influenced by other variables that are not filed in this research
\end{abstract}

Keywords : Facilities, services, tourism destinations, events, interest in visits

\section{PENDAHULUAN}

\section{Latar Belakang}

Banjarnegara adalah salah satu Kabupaten yang menjadi tujuan wisata di
Jawa Tengah yang memiliki potensi alam, budaya, dan kuliner. Pemerintah Kabupaten Banjarnegara Jawa Tengah mengintensifkan perkembangan wisata edukasi guna untuk meningkatkan jumlah 
wisatawan ke wilayah setempat. Untuk itu Pemerintah Kabupaten Baanjarnegara membangun dan mengedepankan sector pariwisata yang telah ada untuk dijadikan penggerak perekonomian. Diharapkan dengan adanya sector ini pariwisata dapat memanfaatkan tenaga kerja masyarakat sekitar sebagai pengelola juga mengurangi pengangguran dan berdampak pada sektor-sektor lain sehingga meningkatkan kesejahteraan rakyat Banjarnegara. Salah satu wisata yang ada di Banjarnegara adalah "Serulingmas".

Serulingmas interactive zoo berada $1 \mathrm{~km}$ dari pusat kota Banjarnegara kearah barat dan bisa dicapai dengan angkutan umum. Salah satu alasan Serulingmas yang awalnya dikelola oleh Pemerintah dan kini dikelola Perumda adalah untuk lebih meningkatkan pendapatan wisata kebun bidatang tersebut. Serulingmas interactive zoo juga menyediakan beerbagai macam fasilitas, destinasi wisata yang menarik, dan event yang menarik juga dan tentunya tempat wisata yang nyaman untuk bersama keluarga. Namun dari data yang didapat adanyata penurunan jumlah kunjungan wisatawan di Serulingmas setelah dikelola pihak swasta dalam hal ini dikelola Perumda.

Jumlah Kunjungan Wisatawan Serulingmas Kabupaten Banjarnegara

Tahun 2014-2019

\begin{tabular}{|c|c|c|c|}
\hline Tahun & $\begin{array}{c}\text { Jumlah kunjungan dikelola } \\
\text { Pemerintah }\end{array}$ & Tahun & $\begin{array}{c}\text { Jumlah kunjungan dikelola } \\
\text { Perumda }\end{array}$ \\
\hline 2014 & 228.499 & 2017 & 183.265 \\
\hline 2015 & 294.106 & 2018 & 231.863 \\
\hline 2016 & 367.416 & 2019 & 265.990 \\
\hline JUMLAH & $\mathbf{8 9 0 . 0 2 1}$ & & $\mathbf{6 8 1 . 1 1 8}$ \\
\hline
\end{tabular}

Sumber : Serulingmas Banjarnegara 2019

Berdasarkan tabel diatas terlihat

bahwa 3 tahun pada saat serulingmas dikelola pemerintah setiap tahun mengalami peningkatan walaupun tidak besar sejumlah $0,5 \%$ dan pada saat serulingmas sudah dikelola pihak Perumda dapat kita lihat 3 tahun kebelakang ada peningkatan dari setiap tahun hanya sebesar $0,3 \%$. Hal ini disebabkan karena disektor pariwisata Banjarnegara banyak munculnya wisata dan desa wisata yang ada di kelola, sehingga para wisata terpecah diberbagai titik wisata. Persaingan yang semakin ketat menyebabkan setiap objek wisata harus menempatkan orientasi pada kepuasan pelanggan sebagai tujuan utama untuk kembali berkunjung (Tjiptono, 2012), hal ini pula yang menjadikan serulingmas interactive zoo mengalami penurunan. Peningkatan yang dilakukan pihak Perumda untuk meningkatkan pendapatan serulingmas interactive zoo agar terus berkembang dengan adanya wisata-wisata lain yang ada di Banjarnegara yaitu dengan memanfaatkan potensi sumber daya alam yang dikembangkan menjadi daya tarik utama wisatawan untuk berkunjung. Untuk meningkatkan jumlah wisatawan harus memperhatikan unsur-unsur yang dapat menarik wisatawan berkunjung sehingga menimbulkan minat untuk datang kembali. Menurut penelitian Kurniawan (2017), bahwa minat merupakan kekuatan pendorong yang menyebabkan seseorang menaruh perhatian pada orang lain atau pada objek lain. Minat merupakan salah 
satu sumber motivasi seseorang untuk melakukan kegiatan yang disukai yang akan berdampak terhadap peningkatan pangsa pasar. Ada 3 (tiga) faktor yang dapat menimbulkan minat seseorang, yaitu faktor dorongan dari dalam, faktor motif sosial dan faktor emosional.

\section{RUMUSAN MASALAH}

1. Apakah Fasilitas berpengaruh terhadap Minat Kunjungan Wisatawan Serulingmas Interactive Zoo?

2. Apakah Pelayanan berpengaruh terhadap Minat Kunjungan Wisatawan Serulingmas Interactive Zoo?

3. Apakah Destinasi Wisata berpengaruh terhadap Minat Kunjungan Wisatawan Serulingmas Interactive Zoo?

4. Apakah Event berpengaruh terhadap Minat Kunjungan Wisatawan Serulingmas Interactive Zoo?

5. Apakah Fasilitas, Pelayanan, Destinasi Wisata dan Event berpengaruh bersama-sama terhadap Minat Kunjungan Wisatawan Serulingmas Interactive Zoo?

\section{METODE PENELITIAN}

\section{Lokasi Penelitan}

Lokasi penelitian yang dipilih oleh penulis dalam penelitian ini yaitu di Serulingmas Interactive Zoo, yang beralamat di Jalan Selamanik No.35, Kec. Banjarnegara, Banjarnegara, Jawa Tengah 53415.

\section{Jenis Penelitian}

Penelitian ini menggunakan data kuantitatif.

\section{Variabel Penelitian}

A .Variabel Independent : Fasilitas(X1), Pelayanan(X2), Destinasi Wisata(X4) dan Event(X5)

B. Variabel Dependent : Minat Kunjungan Wisatawan (Y)

\section{Definisi Konsep dan Definisi Operasional Variabel}

\section{a. Fasilitas}

Definisi konsep : Fasilitas adalah segala sesuatu yang sengaja disediakan oleh penyedia jasa untuk dipakai serta dinikmati oleh konsumen yang bertujuan memberkan tingkat kepuasan maksimal (Kotler 2009).

Definisi operasional : Fasilitas adalah pelengkapan fisik yang disediakan oleh penyedia jasa untuk dapat digunakan oleh konsumen dalam melakukan aktivitasnya.

Indikator : Kelengkapan, kebersihan, dan kerapian fasilitas yang ditawarkan, Kondisi dan fungsi fasilitas yang akan ditawarkan, dan Kemudahan menggunakan fasilitas yang ditawarkan.

\section{b. Pelayanan}

Definisi konsep : Fandy Tjiptono (2012) pelayanan adalah tingkat keunggulan yang diharapkan dan pengendalian atas tingkat keunggulan tersebut untuk memenuhi keinginan pelanggan.

Definisi Operasional : Pelayanan merupakan suatu proses pemberian bantuan yang diberikan oleh organisasi atau perusahaan kepada seseorang atau organisasi yang berlangsung secara rutin dan berkesinambungan yang pada hakikatnya untuk memenuhi kebutuhan. 
Indikator : Bukti langsung (Tangibles) ,Keandalan (Reliability),Daya Tanggap (Responsiveness), Jaminan (Assurance), Empati (Empathy), dan Kecepatan, Ketepatan, Keramahtamahan, Keamanan dan Kenyamanan.

\section{c. Destinasi Wisata}

Definisi konsep : Pitana dan Diarta (2010),menyatakan bahwa kawasan wisata (destinasi) merupakan suatu tempat yang tidak saja menyediakan segala sesuatu yang dapat dilihat wisatawan, namun juga menawarkan aktivitas yang dapat dilakukan pada tempat tersebut dan menjadi daya tarik yang memikat orang untuk berkunjung ke tempat tersebut.

Definisi operasional : Destinasi wisata adalah kawasan geografis yang berada dalam suatu atau lebih wilayah administratif yang di dalamnya terdapat daya tarik wisata, fasilitas umum, fasilitas pariwisata, akesesibilitas, serta masyarakat yang saling terkait dan melengkapi terwujudnya kepariwisataan.

Indikator : Atraksi, Amenitas, dan Aksebilitas.

\section{d. Event}

Definisi konsep : Menurut Noor (2014) event adalah sebagai suatu kegiatan yang diselenggarakan untuk mempengaruhi hal-hal penting, baik secara individu atau kelompok.

Definisi operasional : Event adalah suatu kegiatan atau fenomena hidup yang di lakukan untuk merayakan, menghibur dan menerangkan orang-orang yang terlibat didalamnya dan ada maksud tujuan tertentu .

Indikator :Servise, Price, dan Accessibility.

\section{e. Minat Kunjungan}

Definisi konsep : Philip Kotler (2015) mengasumsikan bahwa minat pembelian pada konsumen dapat disamakan dengan minat berkunjung pada wisatawan. Hal tersebut dapat dilihat pada perilaku yang sama. Konsumen atau Wisatawan dalam memutuskan untuk berkunjung memiliki berbagai pertimbangan seperti halnya sebelum melakukan pembelian.

Definisi operasional : Minat adalah suatu kecenderungan seseorang dalam bertingkah laku yang dapat diarahkan untuk memperhatikan suatu obyek atau melakukan suatu aktivitas tertentu yang didorong oleh perasaan senang karena bermanfaat bagi dirinya sendiri.

Indikator : Rencana mengunjungi kembali, Minat Referensi kunjungan, Minat preferensi kunjungan, dan Minat Eksploratif kunjungan.

\section{Populasi Sampel dan Teknik Sampling}

\section{a. Populasi Penelitian}

Populasi dalam penelitan ini sebanyak 265.990 pengunjung.

\section{b. Sampel}

Sampel penelitian setelah menggunakan Teknik Slovin sebanyak 99 pengunjung atau dibulatkan menjadi 100 pengunjung.

\section{c. Teknik Sampling}

Teknik pengambilan sampel dalam penelitian ini menggunakan teknik Simple Random Sampling.

\section{Teknik Analisis Data}

Adapun teknik analisis data yang digunakan dalam penelitian ini adalah :

a. Uji Instrumen, terdiri dari : 


\section{Uji Validitas \\ 2. Uji Reabilitas}

b. Uji Asumsi Klasik, terdiri dari :

1. Uji Normalitas

2. Uji Multikolinearitas

3. Uji Heteroskedastisitas

c. Teknik Analisis Data dan Uji Hipotesis, terdiri dari :

1. Regresi Berganda

2. Uji Hipotesis
a. Uji t
b. Uji F
c. Uji Koefiseien Determinasi

\section{HASIL DAN PEMBAHASAN \\ Uji Instrumen \\ a. Uji Validitas}

Hasil Uji Validitas Fasilitas

\begin{tabular}{ccccc}
\hline Variable & Item & $\begin{array}{c}\text { Pearson } \\
\text { Correlation }\end{array}$ & Sig & Ket \\
\cline { 1 - 1 } Fasilitas & FSL1 & 0.702 & 0.000 & Valid \\
(X1) & FSL2 & 0.576 & 0.000 & Valid \\
& FSL3 & 0.761 & 0.000 & Valid \\
& FSL4 & 0.400 & 0.000 & Valid \\
& FSL5 & 0.627 & 0.000 & Valid \\
& FSL6 & 0.442 & 0.000 & Valid \\
& FSL7 & 0.426 & 0.000 & Valid \\
& FSL8 & 0.685 & 0.000 & Valid \\
& FSL9 & 0.677 & 0.000 & Valid \\
& FSL10 & 0.682 & 0.000 & Valid \\
\hline
\end{tabular}

Sumber : Hasil Output SPSS

Hasil Uji Validitas Pelayanan

\begin{tabular}{lcccc}
\hline Variable & Item & $\begin{array}{c}\text { Pearson } \\
\text { Correlation }\end{array}$ & Sig & Ket \\
\hline Pelayanan & PLY1 & 0.712 & 0.000 & Valid \\
(X2) & PLY2 & 0.617 & 0.000 & Valid \\
& PLY3 & 0.671 & 0.000 & Valid \\
& PLY4 & 0.660 & 0.000 & Valid \\
& PLY5 & 0.734 & 0.000 & Valid \\
& PLY6 & 0.806 & 0.000 & Valid \\
& PLY7 & 0.660 & 0.000 & Valid \\
& PLY8 & 0.679 & 0.000 & Valid \\
& PLY9 & 0.715 & 0.000 & Valid \\
& PLY10 & 0.428 & 0.000 & Valid \\
\hline
\end{tabular}

Sumber : Hasil Output SPS
Hasil Uji Validitas Destinasi Wisata

\begin{tabular}{lcccc}
\hline Variable & Item & $\begin{array}{c}\text { Pearson } \\
\text { Correlation }\end{array}$ & Sig & Ket \\
\cline { 1 - 2 } Destinasi & DW1 & 0.482 & 0.000 & Valid \\
Wisata & DW2 & 0.432 & 0.000 & Valid \\
(X3) & DW3 & 0.603 & 0.000 & Valid \\
& DW4 & 0.655 & 0.000 & Valid \\
& DW5 & 0.490 & 0.000 & Valid \\
& DW6 & 0.776 & 0.000 & Valid \\
& DW7 & 0.607 & 0.000 & Valid \\
& DW8 & 0.699 & 0.000 & Valid \\
& DW9 & 0.646 & 0.000 & Valid \\
\hline
\end{tabular}

Sumber : Hasil Output SPSS

Hasil Uji Validitas Destinasi Event

\begin{tabular}{lcccc}
\hline Variable & Item & $\begin{array}{c}\text { Pearson } \\
\text { Correlation }\end{array}$ & Sig & Ket \\
\cline { 1 - 2 } Event & EVN1 & 0610 & 0.000 & Valid \\
(X4) & EVN2 & 0.704 & 0.000 & Valid \\
& EVN3 & 0.698 & 0.000 & Valid \\
& EVN4 & 0.615 & 0.000 & Valid \\
EVN5 & 0.643 & 0.000 & Valid \\
& EVN6 & 0.405 & 0.000 & Valid \\
EVN7 & 0.462 & 0.000 & Valid \\
& EVN8 & 0.691 & 0.000 & Valid \\
EVN9 & 0.431 & 0.000 & Valid \\
\hline Sumber : Hasil Output SPSS & & \\
\multicolumn{4}{c}{ Hasil Uji Validitas Minat Kunjungan }
\end{tabular}

\begin{tabular}{lcccc}
\hline Variable & Item & $\begin{array}{c}\text { Pearson } \\
\text { Correlation }\end{array}$ & Sig & Ket \\
\cline { 1 - 2 } Minat & MK1 & 0.546 & 0.000 & Valid \\
Kunjungan & MK2 & 0.552 & 0.000 & Valid \\
(Y) & MK3 & 0.600 & 0.000 & Valid \\
& MK4 & 0.706 & 0.000 & Valid \\
& MK5 & 0.693 & 0.000 & Valid \\
& MK6 & 0.662 & 0.000 & Valid \\
& MK7 & 0.742 & 0.000 & Valid \\
\hline
\end{tabular}

Sumber : Hasil Output SPSS

Berdasarkan tabel diatas dapat dilihat bahwa masing-masing table memiliki nilai pearson correlation diatas 0,05. Hal ini berarti nilai person correlation dinyatakan valid. 


\section{b. Uji Reabilitas}

Hasil Uji Reliabilitas

\begin{tabular}{llll}
\hline No & Variabel & $\begin{array}{c}\text { Cronbach's } \\
\text { Alpha }\end{array}$ & \multicolumn{1}{c}{ Ket } \\
\hline 1. & Failitas & 0.747 & Reliabel \\
2. & Pelayanan & 0.763 & Reliabel \\
& Destinasi & & \\
3. & Wisata & 0.748 & Reliabel \\
4. & Event & 0.726 & Reliabel \\
& Minat & & \\
5. & Kunjungan & 0.759 & Reliabel \\
\hline \multicolumn{2}{l}{ Sumber: Hasil Output } & SPSS &
\end{tabular}

Berdasarkan tabel diatas bahwa nilai Cronbach's Alpha untuk semua variable diatas 0,06 . Sehingga indicator yang dighunakan dinyakan reliabel.

\section{Uji Asumsi Klasik}

\section{a. Uji Normalitas}

\begin{tabular}{lr}
\hline & \multicolumn{2}{c}{ Standardized } \\
Residual & 100 \\
\hline $\mathrm{N}$ & .0000000 \\
Normal & .97958969 \\
Parameters $^{\mathrm{a}, \mathrm{b}}$ & .071 \\
Most Extreme & .071 \\
Differences & -.046 \\
& .071 \\
Kolmogorov-Smirnov Z & .200 \\
Asymp. Sig. (2-tailed) & \\
\hline a. Test distribution is Normal. & \\
b. Calculated from data. &
\end{tabular}

Tabel diatas menunjukkan bahwa nilai signifikansi (Asymp. Sig. 2-tailed) sebesar 0,200. Karena nilai signifikansi lebih besar dari 0,05 sehingga nilai residual berdistribusi normal.

\section{b. Uji Multikolinearitas}

\begin{tabular}{lcl}
\hline \multicolumn{1}{c}{ Variabel } & VIF & \multicolumn{1}{c}{ Ket } \\
\hline Fasilitas & 2,650 & $\begin{array}{l}\text { Bebas } \\
\text { multikolinieritas }\end{array}$ \\
Pelayanan & 2,489 & $\begin{array}{l}\text { Bebas } \\
\text { multikolinieritas }\end{array}$ \\
$\begin{array}{l}\text { Destinasi } \\
\text { Wisata }\end{array}$ & 1,814 & $\begin{array}{l}\text { Bebas } \\
\text { multikolinieritas }\end{array}$ \\
Event & 1,623 & $\begin{array}{l}\text { Bebas } \\
\text { multikolinieritas }\end{array}$ \\
\hline Sumber: Hasil Output SPSS &
\end{tabular}

Sumber: Hasil Output SPSS

Berdasarkan table diatas nilai VIF setiap variable lebih besar dari 10. Maka dapat disimpulkan pada model regresi tidak terjadi gejala multikolinearitas.

\section{Uji Heteroskedastisitas}

\begin{tabular}{|c|c|c|c|c|c|}
\hline & \multicolumn{2}{|c|}{$\begin{array}{c}\text { Unstandardized } \\
\text { Coefficients }\end{array}$} & $\begin{array}{c}\text { Standar } \\
\text { dized } \\
\text { Coeffici } \\
\text { ents }\end{array}$ & T & Sig. \\
& B & Std. Error & Beta & & \\
\cline { 2 - 5 } & 2.753 & 1.244 & - & 2.212 & .029 \\
Fanstant $)$ & -.041 & .046 & -.145 & -.879 & .381 \\
Pelayanan & -.018 & .042 & -.068 & -.427 & .670 \\
Destinasi & .020 & .050 & .054 & .399 & .691 \\
Wisata & .021 & .041 & .066 & .509 & .612 \\
Event & .021 &
\end{tabular}

Dependent Variable: ABS_RES

Dari table diatas masing-masing variable memiliki nilai sigfinikansi $>0,05$ maka dapat disimpulkan model regresi tidak terjadi heteroskedastisitas. 


\section{Teknik Analisis Data dan Uji Hipotesis}

\section{a.Regresi Berganda dan Uji t}

Coefficients $^{\mathbf{a}}$

\begin{tabular}{|c|c|c|c|c|c|c|}
\hline \multirow[t]{2}{*}{ Model } & \multicolumn{2}{|c|}{$\begin{array}{c}\text { Unstandardized } \\
\text { Coefficients }\end{array}$} & \multicolumn{2}{|c|}{$\begin{array}{l}\text { Standardized } \\
\text { Coefficients } \\
\end{array}$} & \multirow[b]{2}{*}{$\mathrm{T}$} & \multirow[b]{2}{*}{ Sig } \\
\hline & B & $\begin{array}{l}\text { Std. } \\
\text { Error }\end{array}$ & Beta & & & \\
\hline 1 (Constant) & 6.931 & 2.098 & - & & 3.303 & .001 \\
\hline Fasilitas & .270 & .078 & & .416 & 3.451 & .001 \\
\hline Pelayanan & .163 & .071 & & .268 & 2.292 & .024 \\
\hline $\begin{array}{l}\text { Destinasi } \\
\text { Wisata }\end{array}$ & .005 & .084 & & .006 & .059 & .953 \\
\hline Event & .071 & .069 & & .097 & 1.026 & .307 \\
\hline
\end{tabular}

a. Dependent Variable: Minat Kunjungan

\section{Pengaruh Fasilitas Terhadap Minat Kunjungan Wisatawan Serulingmas Interactive Zoo}

Dari tabel diatas dapat diketahui bahwa $\mathrm{t}$ hitung 3.451 dengan nilai probability value untuk variabel fasilitas sebesar $0,001<0,05$. Koefisien regresi variabelfasilitas mempunyai nilai yang positif yaitu 0,270 . Hal ini berarti secara parsial fasilitas berpengaruh positif dan signifikan terhadap minat kunjungan. Dengan demikian dapat disimpulkan bahwa $\mathrm{H}_{1}$ diterima.

$\mathrm{H}_{1}$ : Fasilitas berpengaruh positif dan signifikan terhadap Minat Kunjungan Wisatawan Serulingmas Interactive Zoo.

\section{Pengaruh Pelayanan Terhadap Minat Kunjungan Wisatawan Serulingmas Interactive Zoo}

Variabel pelayanan mempunyai $\mathrm{t}$ hitung 2.292 dengan nilai probability value sebesar $0,024<0,05$. Koefisien regresi variabel pelayanan mempunyai nilai yang positif yaitu 0,163 . Hal ini berarti secara parsial pelayanan berpengaruh positif dan signifikan terhadap minat kunjungan. Dengan demikian dapat disimpulkan bahwa $\mathrm{H}_{2}$ diterima.

$\mathrm{H}_{2}$ : Pelayanan berpengaruh positif dan signifikan terhadap Minat Kunjungan Wisatawan Serulingmas Interactive Zoo.

\section{Destinasi Wisata Terhadap Minat} Kunjungan Wisatawan Serulingmas Interactive Zoo

Variabel destinasi wisata $\mathrm{t}$ hitung 0.059 dengan nilai probability value sebesar 0,953 > 0,05. Koefisien regresi variabel destinasi wisata mempunyai nilai yang positif yaitu 0,005 . Hal ini berarti secara parsial destinasi wisata berpengaruh positif dan tidak signifikan terhadap minat kunjungan. Dengan demikian dapat disimpulkan bahwa $\mathrm{H}_{3}$ ditolak.

$\mathrm{H}_{3}$ : Destinasi Wisata berpengaruh positif dan tidak signifikan terhadap Minat Kunjungan Wisatawan Serulingmas Interactive Zoo.

\section{Pengaruh Event Terhadap Minat} Kunjungan Wisatawan Serulingmas Interactive Zoo

Variabel event $\mathrm{t}_{\text {hitung }} 1.026$ dengan nilai probability value mempunyai probability value sebesar 0,0307 < 0,05. Koefisien regresi event mempunyai nilai yang positif yaitu 0,071 . Hal ini berarti secara parsial event berpengaruh positif dan tidak signifikan terhadap minat kunjungan. Dengan demikian dapat disimpulkan bahwa $\mathrm{H}_{4}$ ditolak.

$\mathrm{H}_{4}$ : Event berpengaruh positif dan tidak signifikan terhadap Minat 
Kunjungan

Wisatawan

Serulingmas Interactive Zoo.

\section{Uji F}

\begin{tabular}{|c|c|c|c|c|c|}
\hline \multicolumn{6}{|c|}{ ANOVA $^{\mathrm{a}}$} \\
\hline Model & $\begin{array}{l}\text { Sum of } \\
\text { Squares }\end{array}$ & Df & $\begin{array}{c}\text { Mean } \\
\text { Square }\end{array}$ & $\mathrm{F}$ & Sig. \\
\hline $\begin{array}{ll}1 & \text { Regression }\end{array}$ & 600.603 & 4 & 150.151 & 21.766 & $.000^{\mathrm{a}}$ \\
\hline Residual & 655.357 & 95 & 6.898 & & \\
\hline Total & 1255.960 & 99 & & & \\
\hline
\end{tabular}

a. Dependent Variable: Minat Kunjungan

b. Predictors: (Constant), Fasilitas, Pelayanan, Destinasi

Wisata dan Event

Pengaruh Fasilitas, Pelayanan, Destinasi Wisata dan Event Terhadap Minat Kunjungan Wisatawan Serulingmas Interactive Zoo

Tabel hasi uji $\mathrm{F}$ diatas menunjukkan bahwa $\mathrm{F}_{\text {hitung }} 21.766$ dengan nilai probability value sebesar 0,000 atau lebih kecil dari 0,05. Maka dapat disimpulkan bahwa $\mathrm{H}_{\mathrm{a}}$ diterima dan $\mathrm{H}_{0}$ ditolak. Dengan demikian Fasilitas, Pelayanan, Destinasi Wisata dan Event secara bersama-sama mempunyai pengaruh yang signifikan terhadap Minat Kunjungan.

$\mathrm{H}_{5}$ : Fasilitas, Pelayanan, Destinasi

Wisata dan Event secara bersamasama berpengaruh positif dan signifikan terhadap Minat Kunjungan Wisatawan Serulingmas Interactive Zoo.

\section{Uji Koefisien Determinasi $\left(\mathbf{R}^{\mathbf{2}}\right)$}

\section{Model Summary}

\begin{tabular}{|c|c|c|c|c|}
\hline Model & $\mathbf{R}$ & $\begin{array}{c}\mathbf{R} \\
\text { Square }\end{array}$ & $\begin{array}{c}\text { Adjusted } \\
\text { R } \\
\text { Square }\end{array}$ & $\begin{array}{l}\text { Std. } \\
\text { Error } \\
\text { of the } \\
\text { Estim } \\
\text { ate }\end{array}$ \\
\hline 1 & $.692^{a}$ & .478 & .456 & 2.626 \\
\hline
\end{tabular}

Berdasarkan tabel diatas, diketahui bahwa gabungan korelasi $\mathrm{R}$ dari keempat variabel independen sebesar 0,692 sedangkan koefisien determinasi sebesar $0,478(47,8 \%)$, artinya secara prosentase pengaruh variabel independen yaitu fasilitas, pelayanan, destinasi wisata dan event terhadap minat kunjungan sebesar $47,8 \%$ sedangkan sisanya $52,2 \%$ dipengaruhi oleh variabel lainnya yang tidak dimasukan dalam penelitian ini.

\section{PEMBAHASAN}

\section{Pengaruh Fasilitas Terhadap Minat Kunjungan Wisatawan Serulingmas Interactive Zoo}

Hasil Penelitian ini dapat dilihat bahwa variable fasilitas mempunyai pengaruh positif dan signifikan terhadap minat berkunjung. Hal ini dapat dilihat dari nilai rata-rata persentase yang baik pada tiap indikator fasilitas yaitu kelengkapan, kebersihan dan kerapian fasilitas, kondisi dan fungsi fasilitas, dan kemudahan menggunakan fasilitas. Responden menyatakan bahwa fasilitas yang disediakan oleh Serulingmas Interactive Zoo sudah baik menyatakan sikap positif terhadap fasilitas yang disediakan meliputi kenyamanan fasilitas yang disediakan, kondisi peralatan yang terawat, fasilitas yang masih berfungsi dengan baik dan fasilitas yang mudah digunakan.

Pencapaian kepuasan pengunjung tidak terlepas dari bagaimana fasilitas yang disediakan oleh perusahaan. Fasilitas disediakan untuk menambah nilai dari sebuah layanan jasa. Jika melihat hasil penelitian yang menunjukan fasilitas berpengaruh terhadap kepuasan pengunjung sehingga pengunjung mermpunyai minat untuk kembali lagi, maka perusahaan harus mampu 
memberikan fasilitas yang optimal. Dengan terpenuhinya fasilitas kebutuhan pengunjung, Ia akan dapat menilai apakah manfaat yang diterima sesuai dengan harapan yang dibangunnya. Hal tersebut sesuai dengan teori Tjiptono (2014) bahwa kepuasan konsumen merupakan respon evaluasi yang dirasakan atas harapan an kinerja actual atau manfaat yang dirasakan setelah menikmati layanan jasa.

Hasil penelitian ini konsisten dengan penelitian Nyoman (2018) dan Rosita dkk (2016) yang menyimpulkan bahwa fasilitas memiliki pengaruh yang positif dan signifikan terhadap minat kunjungan. Kelengkapan fasilitas wisata yang nyaman dan aman untuk digunakan dapat meningkatkan jumlah kunjungan wisata, meningkatkan kunjungan wisatawan untuk berada di kawasan tersebut serta berdampak pada peningkatan jumlah pendapatan Serulingmas Interactive Zoo. Namun sebaliknya apabila fasilitas yang terdapat di Serulingmas Interactive Zoo tidak nyaman dan tidak lengkap maka jumlah pengunjung juga akan berkurang yang akhirnya berdampak pada penurunan pendapatan.

\section{Pengaruh Pelayanan Terhadap Minat Kunjungan Wisatawan Serulingmas Interactive Zoo}

Hasil penelitian ini dapat dilihat bahwa variable pelayanan mempunyai pengaruh positif dan signifikan terhadap minat berkunjung. Pelayanan yang diberikan oleh Serulingmas Interactive Zoo merupakan faktor yang sangat berperan sebagai dasar bagi pengunjung untuk memanfaatkan jasa wisata yang sudah diberikan pihak Serulingmas. Kualitas pelayanan adalah hal yang sangat penting dalam persaingan pasar yang sangat kompetitif seperti saat ini, tetapi tidak semua pengunjung atau konsumen menjadikan kualitas pelayanan adalah faktor utama yang membuat wisatawan berkunjung kembali. Hasil penelitian menunjukkan bahwa semakin baik kualitas pelayanan yang diberikan, maka semakin tinggi kepuasan yang dirasakan pengunjung. Dan sebaliknya semakin buruk kualitas pelayanan, maka semakin rendah pengunjung kepuasan yang dirasakan pengunjung.Hal tersebut sesuai dengan teori yang diungkapkan Tjiptono (2014) bahwa kualitas pelayanan merupakan kontribusi keberhasilan suatu perusahaan yang mampu menciptakan presepsi positif dari konsumen serta mampu menghasilkan kepuasan

Hasil penelitian ini konsisten dengan Rosita dkk (2016) juga penelitian menurut Poppy dkk (2016), menyimpulkan bahwa pelayanan berpengaruh positif dan signifikan terhadap minat kunjungan wisatawan.Pengaruh pelayanan terhadap minat kunjungan wisatawan memiliki pengaruh secara langsung yang positif dan signifikan. Artinya pelayanan yang telah diberikan kepada wisatawan di wisata Serulingmas Interactive Zoo berada dalam kategori baik dan dapat memberikan kepuasan kepada wisatawan yang berkunjung. Sehingga ketika pelayanan yang diberikan telah maksimal dan baik maka kepuasan pengunjung pun meningkat. 
Pengaruh Destinasi Wisata Terhadap

Minat Kunjungan Wisatawan

Serulingmas Interactive Zoo

Hasil penelitian ini dapat dilihat bahwa variable destinasi wisata tidak berpengaruh dan tidak signifikan terhadap minat berkunjung. Destinasi pada hakekatnya adalah merupakan suatu tempat atau kawasan geografis yang berada dalam satu atau lebih wilayah administratif yang didalamnya terdapat unsur daya tarik, fasilitas, dan masyarakat yang saling terkait dan melengkapi untuk mewujudkan kegiatan kepariwisataan, citra destinasi (destination image) merupakan keyakinan/pengetahuan mengenai suatu destinasi dan apa yang dirasakan oleh wisatawan selama berwisata atau sering juga di sebut gambaran, pikiran, kepercayaan, perasaaan dan persepsi terhadap suatu destinasi.

Destinasi yang dimiliki wisata Serulingmas Interactive Zoo dalam pandangan beberapa orang merupakan citra destinasi yang mewarkan pemandangan dan perasaan yang kurang bagus, karena memiliki destinasi yang terkesan sangat minim mulai dari pemandangan yang hanya sungai serayu dan juga untuk destinasi lainnya masih sangat kurang dimana permainan anak sudah tidak layak pakai semenjak masih dikelola oleh Pemerintah Daerah dan juga destinasi lain yang tidak setiap hari buka, melainkan hanya setiap 1 minggu sekali. Menurut Fuat Musthofa (2019) bahwa destinasi wisata tidak berpengaruh signifikan terhadap revisit intention (minat berkunjung kembali).
Daya tarik destinasi wisata merupakan faktor utama yang menarik wisatawan dalam mengadakan perjalanan mengunjungi suatu tempat, baik suatu tempat primer yang menjadi tujuan utamanya, atau tujuan sekunder yang dikunjungi dalam suatu perjalanaan primer karena keinginannya untuk menyaksikan, merasakan, dan menikmati daya tarik tujuan tersebut.

Perilaku wisatawan di masa depan yang menilai positif terhadap citra suatu destinasi pariwisata kemungkinan adalah mengunjungi kembali dan merekomendasikan destinasi pariwisata terkait kepada orang lain dengan catatan destinasi yang dikunjungi sangat menarik namun sebaliknya apabila destinasi yang dikunjungi tidak menarik dan tidak berkesan maka wisatawan tidak akan kembali lagi ke tempat tersebut dan bahkan cenderung akan menceritakan ke orang lain. Mempromosikan destinasi wisata dengan gencar agar semakin menarik minat wisatawan untuk berkunjung merupakan salah satu bagian agar Serulingmas Interactive Zoo banyak dikunjungi kembali oleh wisatawan.

\section{Pengaruh Event Terhadap Minat Kunjungan Wisatawan Serulingmas Interactive Zoo}

Hasil penelitian ini dapat dilihat bahwa variable event tidak berpengaruh dan tidak signifikan terhadaminat berkunjung. Event merupakan salah satu cara yang ampuh dalam menyampaikan pesan sebuah brand yaitu dengan mengajak wisatawan yang berkunjung untuk terlibat dalam sebuah event yang diselenggarakan tempat wisata. Event seharusnya merupakan salah satu variabel 
yang memberikan pengaruh signifikan pada wisatawan untuk membentuk minat berkunjung kembali.

Hal ini sama dengan penelitian terdahulu yang sudah pernah diteliti oleh Intan (2016) yang mengemukakan bahwa event tidak berpengaruh dan tidak signifikan terhadap minat beli suatu produk.

Variabel event tidak mempunyai pengaruh signifikan terhadap minat kunjungan wisatawan di Serulingmas Interactive Zoo. Hal ini menunjukkan bahwa banyak sekali faktor yang mempengaruhi diantaranya yaitu keadaan cuaca yang diluar kendali. Misalnya saja hujan deras yang tidak kunjung berhenti atau angin puting beliung yang tiba-tiba datang sehingga menyebabkan jalannya event mundur sedangkan disisi lain event yang dijalankan mempunyai durasi waktu karena terkait dengan ijin, hingga akhirnya target wisatawan yang diharapkan tidak sesuai. Selain itu faktor lain dalam event yang ada di Serulingmas Interactive Zoo seperti event mingguan yang di awal-awal selalu ada sesuai jadwal namun akhir-akhir ini tidak ada lagi dan event yang ditampilkan juga membosankan. Event monoton seperti ini yang menyebabkan pengunjung kurang berminat untuk berkunjung kembali.

Data event Serulingmas Interactive Zoo

\begin{tabular}{|l|l|}
\hline $\begin{array}{l}\text { Waktu } \\
\text { Event }\end{array}$ & Kegiatan/Acara \\
\hline Mingguan & $\begin{array}{l}\text { - Musik minggu pagi } \\
\text { - Senam pagi bersama } \\
\text { (sudah tidak ada) }\end{array}$ \\
\hline Bulanan & $\begin{array}{l}\text { Disesuaikan dengan acara } \\
\text { pada bulan-bulan tertentu } \\
\text { (Acara Barongsai pada saat } \\
\text { bulan Imlek) }\end{array}$ \\
\hline Tahunan & $\begin{array}{l}\text { Pekan Lebaran } \\
\text { Dagdut) }\end{array}$ \\
\hline
\end{tabular}

Hendaknya lebih memperhatikan kembali variabel event, karena dimasa yang akan datang startegi pemasaran akan lebih beragam bentuknya. Tentunya ideide yang kreatif dan inovasi dari berbagai kalangan akan sangat diperlukan demi keberhasilan suatu peningkatan wisatawan untuk berkunjung. Apabila Serulingmas masih sama dalam mengadakan event seperti ini bisa dipastikan minat kunjungan wisatawan yang berkunjung ke Serulingmas Interactive Zoo akan menurun. Penyelenggaraan event positif akan mempengaruhi keputusan berkunjung wisatawan begitupun sebaliknya

Pengaruh Fasilitas, Pelayanan, Destinasi Wisata dan Event secara simultan terhadap Minat Kunjungan Wisatawan Serulingmas Interactive Zoo

Hasil penelitian ini dapat dilihat bahwa variable Fasilitas, Pelayanan, Destinasi Wisata, dan Event berpengaruh yang signifikan secara bersama-sama atau secara simultan terhadap Minat Kunjungan Wisatawan Serulingmas Interactive Zoo. Pencapaian kepuasan minat berkunjung kembali wisatawan tidak terlepas dri bagaimana fasilitas, pelayanan, destinasi wisata, dan event yang disediakan oleh perusahaan dalam upaya pemenuhan kebutuhan pengunjung.

Hasil penelitian ini konsisten dengan penelitian Zaenuri (2012) berpendapat bawa daya tarik wisata yang didukung dengan fasilitas, pelayanan dan beberapa faktor lainnya juga dapat meningkatkan minat dan loyalitas wisatawan dan secara bersama-sama mempunyai pengaruh terhadap Minat Kunjungan Wisatawan. 


\section{KESIMPULAN}

Dari pembahasan yang telah diuraikan, maka dapat disimpulkan sebagai berikut :

1. Hasil pengujian membuktikan bahwa fasilitas memiliki pengaruh positif dan signifikan terhadap minat kunjungan.

2. Hasil pengujian membuktikan bahwa pelayanan memiliki pengaruh positif dan signifikan terhadap minat kunjungan.

3. Hasil pengujian membuktikan bahwa destinasi wisata memiliki pengaruh namun tidak signifikan terhadap minat kunjungan.

4. Hasil pengujian membuktikan bahwa event memiliki pengaruh positif namun tidak signifikan terhadap minat kunjungan.

\section{SARAN}

Berdasarkan kesimpulan yang telah dilakukan maka saran yang dapat diberikan dalam penelitian ini yaitu:

1. Pihak pengelola objek wisata supaya dapat melakukan perawatan secara rutin terhadap sarana yang ada di objek wisata sehingga orang yang datang berkunjung merasa puas dan dapat merekomendasikan objek wisata tersebut agar dapat dikunjungi oleh saudara atau kerabat baik.

2. Peningkatan promosi guna pengembangan pasar wisatawan baik wisatawan dari wilayah Banjarnegara maupun luar wilayah Banjarnegara melaui media cetak maupun elektronik
3. Fasilitas yang diberikan sudah sangat cukup baik dan menarik wisatawan untuk berkunjung, hal ini pengelola perlu mempertahankan dan lebih meningkatkan kualitas fasilitasnya sehingga wisatawan tidak merasa bosan dan mendapatkan kesan yang jauh lebih baik daripada kesan yang sebelumnya setelah berkunjung.

4. Pengelola hendaknya segera menambah fasilititas yang masih kurang dan melengkapi fasilitas untuk wisatawan misalnya perluasan lahan tempat parkir, taman untuk beristirahat, toilet.

5. Prioritas objek wisata Serulingmas Intreactive Zoo yang pembentukannya memerlukan proses waktu yang sangat lama hendaknya dijaga kelestariannya atau kealamiannya baik dari pengelola dan masyarakat setempat.

6. Untuk meningkatkan kualitas pelayanan, maka pengelola dan karyawan harus bekerja sama dalam peningkatan kualitas SDM baik dari segi pendidikan maupun dari segi managementnya. Selain itu prosedur standar oprasional (SOP) yang diberlakukan harus benar-benar diterapkan sehingga pelaksanaan tugas di setiap divisinya berjalan dengan maksimal dan kualitas pelayanan yang diberikan pun semakin prima dan meningkat.

7. Pengelola hendaknya lebih mengatur dan mengecek lagi para pedagang disekitar Serulingmas Interactive Zoo baik dari 
kebersihan dan juga kelengkapan berdagang, jangan sampai ada wisatawan atau pengunjung yang ingin membeli sesuatu tetapi tidak tersedia atau tidak sesuai dengan yanng sudah ditawarkan.

8. Menambah dan melengkapi destinasi yang sudah ada, memperbaiki beberapa kebutuhan penunjang destinasi misalnya mengganti yang sudah tidak layak dengan yang baru.

9. Pengelola pariwisata juga harus lebih mengadakan berbagai hiburan atau event yang variatif untuk menarik minat wisatawan untuk berkunjung. Serulingmas Interactive Zoo merupakan salah satu tempat yang sering digunakan untuk pertujukan seni, tapi sayangnya tempat ini belum banyak diketahui oleh wisatawan. Hal ini dikarenakan kurangnya promosi dari pengelola.

10. Dengan keterbatasan pada penelitian ini, hendaknya penelitian selanjutnya menambah variabel lain yang dapat mempengaruhi Minat Kunjungan. Peneliti mengharapkan kritik dan saran yang membangun dari peneliti dan selanjutnya bisa diteliti dengan tempat berbeda.

\section{DAFTAR PUSTAKA}

Fandy Tjiptono. 2012. Strategi Pemasaran. Yogyakarta: Andi,

Kotler \& Keller. 2012. Marketing Management 14 Edition. Pearson Prentince Hall: Global Edition..

Kotler, Philip and Kevin Lane Keller, 2016. Marketing Managemen, 15th Edition. Pearson

Education,Inc

Kurniawan, Albert. 2017. Metode Riset untuk Ekonomi dan Bisnis: Teori,Konsep, dan Praktik Penelitian Bisnis (Dilengkapi Perhitungan Pengolahan Data dengan IBM SPSS 22.0). Bandung: Alfabeta.

Ni Nyoman Ayu Wirantini, Nyoman Djinar Setiawan, dan Ni Nyoman Yuliarmi. 2018. Analisis FaktorFaktor Yang Mempengaruhi Niat Kunjungan Kembali Wisatawan Pada Daya Tarik Wisata di Kabupaten Bandung, E-jurnal Ekonomi dan Bisnis Universitas Udayana 7.1 (2018): 279-308

Panjaitan, Poppy dan Arik Prasetya. "Pengaruh Sosial Media terhadap Produktivitas Kerja Generasi Millenial (Studi Pada Karyawan PT. Angkasa Pura I Cabang Bandara Internasional Juanda)". Jurnal Administrasi Bisnis (JAB), Vol. 48 No. 1 Juli 2017.

Pitana, I Gede. dan Surya Diarta, I Ketut. 2010. Pengantar Ilmu Pariwisata. Yogyakarta: Penerbit Andi

Rosita, Sri Marhanah,Woro Hanoum Wahadi. 2016." Pengaruh Fasilitas Wisata Dan Kualitas Pelayanan Terhadap Kepuasan Pengunjung Di Taman Margasatwa Ragunan Jakarta". Jurnal Manajemen Resort dan Leisure Vol.13, No.1, Universitas Pendidikan Indonesia.

Zaenuri, Muchamad. 2012. Perencanaan Strategis Kepariwisataan Daerah: Konsep dan Aplikasi, Jogjakarta. e-Gov Publishing. 